OPEN ACCESS

Edited by:

Muthuraman Muthuraman, University Medical Center of the Johannes Gutenberg University Mainz, Germany

Reviewed by: Carlo Alberto Artusi, University of Turin, Italy Alberto Romagnolo,

University of Turin, Italy

*Correspondence: Daniel Weiss daniel.weiss@uni-tuebingen.de

'Statistical analysis was completed by Idil Cebi, Marlieke Scholten, and Daniel Weiss

Specialty section: This article was submitted to Movement Disorders, a section of the journa Frontiers in Neurology

Received: 09 December 2019 Accepted: 09 March 2020

Published: 22 April 2020

Citation:

Cebi I, Scholten M, Gharabaghi A and Weiss D (2020) Clinical and Kinematic Correlates of Favorable Gait Outcomes From Subthalamic Stimulation. Front. Neurol. 11:212. doi: 10.3389/fneur.2020.00212

\section{Clinical and Kinematic Correlates of Favorable Gait Outcomes From Subthalamic Stimulation}

\author{
Idil Cebi ${ }^{1,2,3,4 \dagger}$, Marlieke Scholten ${ }^{1,2,3 \dagger}$, Alireza Gharabaghi ${ }^{3,4}$ and Daniel Weiss ${ }^{1,2,3 * t}$ \\ ${ }^{1}$ Department of Neurodegenerative Diseases, Centre for Neurology, Hertie Institute for Clinical Brain Research (HIH), \\ University of Tübingen, Tübingen, Germany, ${ }^{2}$ German Centre of Neurodegenerative Diseases (DZNE), University of Tübingen, \\ Tübingen, Germany, ${ }^{3}$ Tübingen Neuro Campus (TNC), University of Tübingen, Tübingen, Germany, ${ }^{4}$ Division of Functional \\ and Restorative Neurosurgery, Department of Neurosurgery, University of Tübingen, Tübingen, Germany
}

Objective: Gait and freezing of gait (FoG) are highly relevant to the outcomes of subthalamic nucleus deep brain stimulation (STN-DBS) in Parkinson's disease (PD). Previous studies pointed to variable response to combined dopaminergic and STN-DBS treatment. Here, we performed a prospective exploratory study on associations of preoperative clinical and kinematic gait measures with quantitative gait and FoG outcomes after STN-DBS implantation.

Methods: We characterized 18 consecutive PD patients (13 freezers) before and after STN-DBS implantation. The patients received preoperative levodopa challenges (MedOff vs. MedOn) and a postoperative reassessment at 6 months from surgery in MedOn/StimOn condition. We correlated the FoG outcome, calculated as improvement of Freezing of Gait Assessment Course (FoG-AC) from baseline MedOff to 6-month follow-up MedOn/StimOn, with the levodopa response of preoperative clinical and kinematic gait measures. We considered measures with significant correlations for a multiple regression model.

Results: We found that the postoperative gait and FoG outcomes were associated with the preoperative levodopa response of clinical and kinematic gait measures. In particular, preoperative levodopa sensitivity of FoG showed high correlation with a favorable quantitative FoG outcome. Among kinematic measures, preoperative levodopa response of stride length and range of motion showed high correlation with favorable FoG outcome. In addition, the preoperative levodopa sensitivity of FoG predicted postoperative FoG outcome with high accuracy $\left(R^{2}=0.952 ; 95 \% \mathrm{Cl}\right.$ : 0.95-1.29; $\left.P<0.001\right)$.

Conclusions: Preoperative clinical and kinematic measures correlated with favorable postoperative gait and FoG outcomes. The findings should be reproduced in larger and independent cohorts to verify their predictive value.

Keywords: deep brain stimulation, subthalamic nucleus, freezing of gait, gait kinematics, Parkinson's disease 


\section{INTRODUCTION}

Gait disturbance and freezing of gait (FoG) hamper quality of life and lead to falls and morbidity in Parkinson's disease (PD) $(1,2)$. Given the variable response to dopaminergic medication and deep brain stimulation of the subthalamic nucleus (STNDBS), a preoperative stratification of postoperative gait and FoG outcomes is needed (3-6). Because gait and FoG outcomes did not constitute primary endpoints in previous large-scale, randomized controlled trials, the present evidence is incomplete $(7,8)$. One recent meta-analysis suggested that the levodopa response of the Movement Disorder Society (MDS)-sponsored Revision of the Unified Parkinson's Disease Rating Scale part III (MDS-UPDRS III) summary score indicates favorable FoG outcome (9). A recent secondary analysis of the EARLYSTIM cohort found that the patients with preoperative FoG were more likely to stay freezers at 24-month follow-up when having longer disease duration (10).

To improve therapeutic decisions in the context of FoG, finegrained multimodal measures specific to gait and FoG outcomes are needed to account for the complexity of postoperative outcomes of gait. Beyond clinical variables, sensor-based kinematic features receive converging interest in order to achieve objective and quantitative features of PD gait $(11,12)$. Some parameters such as reduction in step length, decreased velocity, increased cadence, stride-to-stride variability (13), and lower limb asymmetry (14) are precursors for FoG and falls (15). Previous studies concluded that both dopaminergic medication and STN-DBS modulated such features alone or in combination (16-20), in particular, stride length, velocity, and range of motion (ROM) at hip, knee, and ankle levels (16-19, 21-23).

In this study, we characterized consecutive patients with idiopathic PD evaluated for STN-DBS therapy with respect to gait measures, and FoG in particular, including clinical and kinematic gait and FoG assessments. First, patients received a diagnostic workup of gait measures in a preoperative levodopa challenge. Then, patients were followed up postoperatively, and both (i) the effect of STN-DBS 8 weeks after surgery and (ii) the overall gait and FoG outcome of combined dopaminergic medication and STN-DBS 6 months after surgery were characterized. The aim of this prospective study was to explore meaningful clinical and kinematic candidate features that correlate with favorable gait and, in specific, quantitative FoG outcomes. With this study, we wished to identify candidate features for a future larger and independent prospective prediction study.

\section{MATERIALS AND METHODS}

The trial was approved by the Ethics Committee of the University of Tübingen (355/2015BO1). All patients participated with written informed consent.

\section{Patients}

We consecutively recruited 24 advanced PD patients among DBS candidates during an inpatient-screening visit between May 2015 and November 2016. Inclusion criteria were disease duration longer than 5 years and age $>18$ and $<80$ years. The presence of FoG was not an inclusion criterion. Exclusion criteria were as follows: cognitive impairment [Mini-Mental State Examination (MMSE) <25], participation in other clinical trials, and chronic pathological conditions interfering with the interpretability of gait assessments (e.g., major orthopedic or psychiatric conditions like depression or psychosis).

Out of the 24 patients, 18 underwent subthalamic nucleus implantation (STN-DBS) according to regular DBS indication criteria $(7,8)$. The remaining six patients stayed under best oral medical treatment. Reasons were sufficient amelioration of tremor $(n=2)$, sufficient amelioration of motor fluctuations $(n=3)$ after optimizing oral medication, or lack of objective motor fluctuations $(n=1)(8,24)$.

The mean age of the study cohort $(n=18)$ was $66.9 \pm 6.9$ years, and mean disease duration was $12.8 \pm 6.0$ years. The median MMSE score was $30[\min 26-\max 30]$. The levodopa equivalent dosage at baseline was $1,334 \pm 147 \mathrm{mg} /$ day. Detailed patient characteristics are given in Table 1.

\section{Study Design}

Patients underwent a preoperative "baseline assessment" in two conditions: (i) clinical off-state after overnight withdrawal of dopaminergic medication (MedOff) and (ii) clinical on-state (MedOn) assessed within $1 \mathrm{~h}$ after intake of immediate release levodopa preparation (1.5-fold individual morning dose). We performed (i) a 7-m timed walking test [Core Assessment Program for Surgical Interventional Therapies in Parkinson's Disease (CAPSIT-PD)], (ii) Freezing of Gait Assessment Course (FoG-AC) for quantitative FoG assessment (25), and (iii) Push and Release Test for assessing postural stability (26). These tests were performed using wearable inertial measurement units (APDM Inc., Portland, OR, USA). Additional clinical characterization included MDS-UPDRS III, Postural Instability and Gait Disorder (PIGD) subscore (sum of items 10-12 from MDS-UPDRS III), and Berg Balance Scale. For the PIGD subscore, we decided to use only clinical motor items 3.10-3.12 from MDS-UPDRS part III. We did not use the MDS-UPDRS II items 2.12 and 2.13, which rely on patient reporting. The main reason for this decision was that we expected MDS-UPDRS II not to be sensitive to the clinical transitions between clinical conditions (i.e., narrow time intervals between preoperative MedOff vs. MedOn and postoperative StimOff vs. StimOn). We further obtained MDS-UPDRS parts I, II, and IV and Parkinson's Disease Questionnaire (PDQ-39) for quality of life.

Eighteen patients underwent surgery for bilateral STN-DBS with Medtronic quadripolar leads, model $3389(n=17)$ or model $3387(n=1)$; and all received an Activa PC impulse generator (Medtronic, Minneapolis, Minnesota). No surgical complications were reported. DBS was turned on within the first week after surgery. Three patients experienced falls in the first 8 weeks after surgery (ID 9 owing to an accident; ID 12 and 20 owing to FoG). One patient required inpatient care and surgery owing to radius fracture. One patient showed psychosis (ID 15) 10 weeks after surgery, which reverted under treatment with clozapine $25 \mathrm{mg} /$ day. An "interim assessment" with a detailed reprogramming session was carried out 8 weeks from surgery after attenuation of the postoperative stun effect (i) to achieve 
TABLE 1 | Patient characteristics at baseline.

\begin{tabular}{|c|c|c|c|c|c|c|c|c|c|c|c|c|}
\hline ID & $\begin{array}{l}\text { Age as } \\
\text { range }\end{array}$ & $\begin{array}{c}\text { Disease } \\
\text { duration } \\
\text { (years) }\end{array}$ & $\begin{array}{l}\text { LEDD } \\
\text { (mg/d) }\end{array}$ & MMSE & $\begin{array}{c}\text { MDS- } \\
\text { UPDRS III } \\
\text { MedOff }\end{array}$ & $\begin{array}{l}\text { MDS- } \\
\text { UPDRS III } \\
\text { MedOn }\end{array}$ & $\begin{array}{c}\text { MDS- } \\
\text { UPDRS } \\
\text { I }\end{array}$ & $\begin{array}{c}\text { MDS- } \\
\text { UPDRS } \\
\text { II }\end{array}$ & $\begin{array}{l}\text { MDS- } \\
\text { UPDRS } \\
\text { IV }\end{array}$ & $\begin{array}{c}\text { H\&Y } \\
\text { stage } \\
\text { MedOff }\end{array}$ & $\begin{array}{c}\text { DBS } \\
\text { indication }\end{array}$ & $\begin{array}{c}\text { Freezing } \\
\text { of gait }\end{array}$ \\
\hline 2 & 50-59 & 7 & 813 & 30 & 51 & 22 & 8 & 10 & 0 & 2 & 2 & 0 \\
\hline 3 & $70-79$ & 17 & 821 & 28 & 67 & 48 & 7 & 31 & 10 & 4 & 1 & 1 \\
\hline 4 & $70-79$ & 5 & $0^{*}$ & 26 & 40 & 29 & 12 & 15 & 0 & 2 & 2 & 0 \\
\hline 5 & $70-79$ & 10 & 2,281 & 30 & 71 & 39 & 3 & 27 & 3 & 4 & 1 & 1 \\
\hline 6 & $70-79$ & 15 & 1,830 & 30 & 40 & 12 & 11 & 25 & 5 & 4 & 1 & 1 \\
\hline 9 & 60-69 & 9 & 1,198 & 30 & 22 & 15 & 8 & 10 & 6 & 3 & 1 & 1 \\
\hline 11 & $70-79$ & 12 & 1,460 & 30 & 55 & 26 & 16 & 11 & 7 & 4 & 1 & 1 \\
\hline 12 & $50-59$ & 10 & 2,069 & 29 & 56 & 22 & 11 & 26 & 5 & 3 & 1 & 1 \\
\hline 14 & $60-69$ & 24 & 2,081 & 29 & 53 & 29 & 15 & 25 & 10 & 3 & 1 & 1 \\
\hline 15 & $60-69$ & 8 & 1,633 & 28 & 57 & 34 & 11 & 26 & 12 & 4 & 1 & 1 \\
\hline 16 & 60-69 & 20 & 833 & 30 & 76 & 45 & 16 & 13 & 8 & 4 & 1 & 1 \\
\hline 17 & $60-69$ & 11 & 800 & 30 & 44 & 30 & 3 & 13 & 3 & 2 & 2 & 0 \\
\hline 18 & $60-69$ & 13 & 1,158 & 30 & 38 & 17 & 13 & 4 & 6 & 2 & 1 & 0 \\
\hline 19 & $70-79$ & 5 & 1,198 & 30 & 45 & 32 & 7 & 13 & 4 & 3 & 1 & 1 \\
\hline 20 & 60-69 & 13 & 1,221 & 30 & 28 & 10 & 9 & 6 & 5 & 3 & 1 & 1 \\
\hline 21 & $70-79$ & 27 & 2,438 & 30 & 38 & 28 & 12 & 24 & 15 & 3 & 1 & 0 \\
\hline 22 & $70-79$ & 13 & 981 & 30 & 36 & 19 & 7 & 15 & 8 & 3 & 1 & 1 \\
\hline 23 & 50-59 & 11 & 1,200 & 29 & 43 & 18 & 16 & 18 & 13 & 3 & 1 & 1 \\
\hline
\end{tabular}

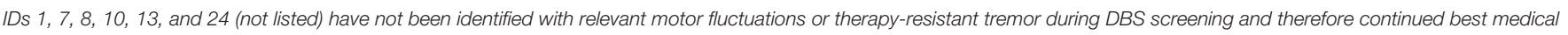

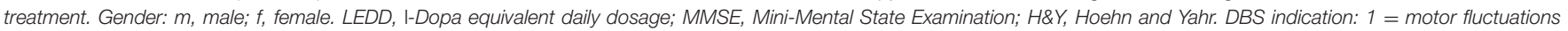

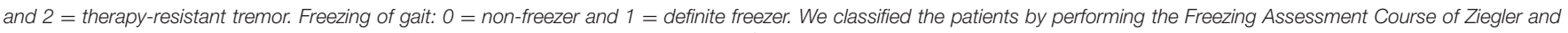
colleagues and by using the Freezer classification algorithm of Snijders and colleagues. 'Patient had therapy-resistant tremor.

optimized stimulation settings and (ii) to determine the pure STN-DBS effect on gait and FoG. This reprogramming session was performed after overnight withdrawal of all dopaminergic medication in MedOff/StimOff and MedOff/StimOn conditions. We performed first MedOff/StimOff assessment about $30 \mathrm{~min}$ after switching the stimulation off and then MedOff/StimOn assessment at least $30 \mathrm{~min}$ after switching the stimulation on. We used a similar approach elsewhere (27). We performed the CAPSIT-PD, the FoG-AC, the Push and Release Test, and MDSUPDRS III in both conditions.

A detailed postoperative characterization was performed 6 months from implantation under the best individual treatment (follow-up MedOn/StimOn). Detailed information on the stimulation parameters is provided (Table e-1). One patient was lost to follow-up after retracting consent (ID 2). We decided for this time point to ensure that the postoperative stun effect would have fully remitted and to ensure that stimulation parameters and medication had been adjusted. We decided for the MedOn/StimOn condition, because we wished to determine the gait and FoG outcome in the treatment state close to the regular daily life conditions. Furthermore, we reasoned that another MedOff session and reinsertion of levodopa by means of a challenge would not have reflected the true daily life outcome. However, this choice also meant that we assessed the pure stimulation effect at the 8-week interim assessment, but not at the postoperative 6-month follow-up. The detailed study protocol is given in Figure 1.

\section{Kinematic Recordings}

Three wearable Opal ${ }^{\circledR}$ inertial measurement units (APDM Inc., Portland, OR, USA) were used for gait kinematic analysis. These sensors comprise tri-axial accelerometer, gyroscope, and magnetometer attached to both ankles and in lumbar position. We computed the kinematic gait measures with the "Mobility Lab" algorithm (APDM Inc., Portland, OR, USA) (28). The spatial (stride length), temporal (gait cycle time), and spatiotemporal (stride velocity) parameters as well as ROM of shanks and knees were extracted. In addition, we computed swing time asymmetry (Equation 1).

$$
\text { Swing time asymmetry }=100 \times \frac{\mid \text { SWTleft }- \text { SWTright } \mid}{\max ([\text { SWTleft, SWTright }])}(1)
$$

In two patients, the quality of the kinematic time series was not adequate for analysis owing to technical problems (ID 3 at follow-up; ID 16 at baseline MedOff).

\section{Outcome Measures and Statistical Analysis}

In this prospective study, we aimed to explore the preoperative clinical and kinematic correlates from a comprehensive set of candidate features potentially related to gait and FoG outcomes.

\section{Quantitative Comparisons of Outcomes Including Levodopa and Stimulation Effects on the Entire Group and on the Freezer Subgroup}

We first assessed the preoperative levodopa response (MedOff vs. MedOn) at "baseline assessment" on clinical gait, FoG, balance 


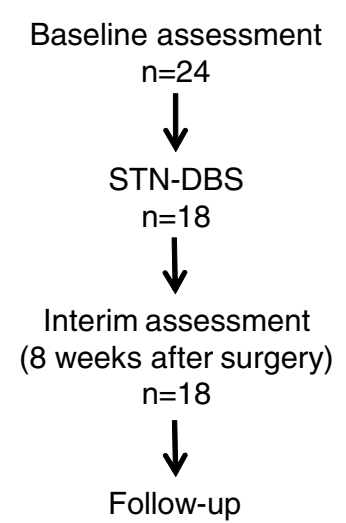

(6 months after surgery) $\mathrm{n}=17$

\begin{tabular}{|c|c|c|c|c|c|}
\hline & \multicolumn{2}{|c|}{ Baseline assessment } & \multicolumn{2}{|c|}{ Interim assessment } & \multirow{2}{*}{$\begin{array}{c}\text { Follow-up } \\
\text { MedOn/ } \\
\text { StimOn }\end{array}$} \\
\hline & MedOff & MedOn & $\begin{array}{l}\text { MedOff/ } \\
\text { StimOff }\end{array}$ & $\begin{array}{l}\text { MedOff/ } \\
\text { StimOn }\end{array}$ & \\
\hline $\begin{array}{l}\text { Freezing of Gait Assessment } \\
\text { Course*}^{*}\end{array}$ & $\mathrm{x}$ & $\mathrm{x}$ & $\mathrm{x}$ & $\mathrm{X}$ & $\mathrm{X}$ \\
\hline MDS-UPDRS III & $x$ & $x$ & $x$ & $x$ & $x$ \\
\hline Push and Release Test ${ }^{*}$ & $x$ & $\mathrm{X}$ & $x$ & $x$ & $x$ \\
\hline Berg Balance Scale & $x$ & $x$ & & & $x$ \\
\hline CAPSIT-PD* & $x$ & $\mathrm{x}$ & $x$ & $x$ & $x$ \\
\hline MDS-UPDRS I & \multicolumn{2}{|c|}{$\mathrm{X}$} & & & $x$ \\
\hline MDS-UPDRS II & \multicolumn{2}{|c|}{$\mathrm{X}$} & & & $x$ \\
\hline MDS-UPDRS IV & \multicolumn{2}{|c|}{$\mathrm{X}$} & & & $\mathrm{x}$ \\
\hline PDQ-39 & \multicolumn{2}{|c|}{$\mathrm{x}$} & & & $\mathrm{x}$ \\
\hline
\end{tabular}

FIGURE 1 | Study design and protocol. *Tests were performed using wearable inertial measurement units (APDM Inc., Portland, OR, USA).

scores, and kinematic measures. Then, we defined the stimulation effect by comparing MedOff/StimOff and MedOff/StimOn conditions during the "interim assessment," which took place 8 weeks from surgery. A comparison of MedOff condition from "baseline assessment" and MedOn/StimOn condition from "follow-up" determines the gait and FoG outcomes. We tested for normal distribution using the Kolmogorov-Smirnov test $(P$ $<0.05$ ). To compare between conditions, we used $t$-test for parametric data, Wilcoxon, or sign test for non-parametric data. We performed the analysis for the entire group and for the freezer subgroup. Patients were classified as definite freezers according to previous criteria (29), that is, if the examiner observed FoG. We corrected the clinical measures as well as the kinematic measures using the false discovery rate (FDR) (30).

\section{Correlations of Preoperative Scores With Postoperative 6-Month Freezing Outcome in the Freezer Subgroup}

We tested whether preoperative clinical and kinematic variables with significant levodopa response correlate with the postoperative 6 months outcome of regular therapy in MedOn/StimOn. We used Spearman correlations to this end.

\section{Prediction of the 6-Month Freezing Outcome From Preoperative Clinical and Kinematic Variables in the Freezer Subgroup}

Owing to the limited sample size of this monocentric study, we did not design the study as a prediction study. However, following an exploratory approach, we evaluated whether valid predictions of the FoG outcomes in terms of FoG-AC (as dependent variable, calculated as improvement of FoG-AC from baseline MedOff to 6-month follow-up MedOn/StimOn) could be made from the preoperative levodopa-sensitive clinical and kinematic measures. This means that we carried forward the preoperative variables (MedOn-MedOff) that showed significant correlation with the postoperative 6 months outcomes of FoG. We considered these findings rather hypothesis-generating instead of confirmatory, owing to the limited sample size and the high selection in this cohort; that is, the findings should be reproduced in independent cohorts. We used a stepwise multiple regression model to this end.

All statistical analyses were performed with IBM SPSS statistics, version 25.0 (IBM Deutschland GmbH, Ehningen, Germany). We report descriptive statistics as mean \pm SD for parametric data and median [min-max] for non-parametric data depending on their distribution.

\section{RESULTS}

\section{Comparison of Gait Outcomes on the Entire Group}

A detailed overview of the statistical descriptives and results of the "entire group" analysis is given in Table 2.

\section{Preoperative MedOff vs. MedOn}

MedOn improved the CAPSIT-PD in "number of steps" $(P=$ $0.001)$ and "time" $(P=0.001)$. We observed an improvement of joint ROM at shank level $(P<0.001)$ and knee level $(P=0.003)$, of stride length $(P=0.001)$, and stride velocity $(P=0.003)$. There was no difference in gait cycle time and swing time asymmetry.

\section{8-Week StimOff vs. StimOn}

CAPSIT-PD showed an improvement with STN-DBS in the "number of steps" $(P=0.004)$ and "time" $(P=0.002)$. Spatiotemporal and kinematic gait parameters showed an improvement of joint ROM at shank level $(P=0.006)$ and at knee level $(P<0.001)$ and of stride length $(P=0.028$, n.s. after FDR correction). There was no difference in stride velocity, gait cycle time, and swing time asymmetry.

\section{Preoperative MedOff vs. 6-Month MedOn/StimOn}

CAPSIT-PD showed an improvement 6 months after STN-DBS implantation in the "number of steps" $(P=0.009)$ and "time" $(P$ $=0.017)$. We observed an improvement of joint ROM at shank level $(P=0.008)$ and knee level $(P=0.005)$ and of stride length $(P$ 
TABLE 2 | Clinical and kinematic data of entire group.

\begin{tabular}{|c|c|c|c|c|c|c|c|c|}
\hline & $\begin{array}{l}\text { Baseline } \\
\text { MedOff }\end{array}$ & $\begin{array}{l}\text { Baseline } \\
\text { MedOn }\end{array}$ & $\begin{array}{c}\text { Interim } \\
\text { MedOff/StimOff }\end{array}$ & $\begin{array}{c}\text { Interim } \\
\text { MedOff/StimOn }\end{array}$ & $\begin{array}{l}\text { Follow-up (FU) } \\
\text { MedOn/StimOn }\end{array}$ & $\begin{array}{c}P \text {-value } \\
\text { Baseline Off } \\
\text { vs. FU }\end{array}$ & $\begin{array}{c}\text { P-value } \\
\text { Baseline } \\
\text { Off vs. On }\end{array}$ & $\begin{array}{c}P \text {-value } \\
\text { Interim } \\
\text { Off vs. On }\end{array}$ \\
\hline MDS-UPDRS III c & $47.78 \pm 14.35$ & $26.39 \pm 10.71$ & $50.39 \pm 16.43$ & $33.33 \pm 11.11$ & $28.88 \pm 11.94$ & $<0.001^{*}$ & $<0.001^{\star}$ & $<0.001^{\star}$ \\
\hline PIGD subscore ${ }^{c}$ & $5.44 \pm 2.92$ & $2.39 \pm 2.09$ & $4.61 \pm 2.89$ & $3.22 \pm 2.58$ & $2.82 \pm 2.74$ & $0.002^{\star}$ & $<0.001^{*}$ & $0.006^{\star}$ \\
\hline Push and release Test ${ }^{a}$ & $1[0-4]$ & $1[0-4]$ & $1[0-4]$ & $1[0-4]$ & $0[0-4]$ & $0.013^{\star}$ & 0.070 & 1.000 \\
\hline Berg balance scale ${ }^{b}$ & $43[9-56]$ & 55 [10-56] & & & $56[11-56]$ & $0.013^{\star}$ & $0.001^{\star}$ & \\
\hline CAPSIT-PD time ${ }^{b}$ & $28[11-533]$ & $16[9-42]$ & $23.5[12-360]$ & $15[9-93]$ & $15[11-257]$ & $0.017^{\star}$ & $0.001^{*}$ & $0.002^{\star}$ \\
\hline CAPSIT-PD steps ${ }^{b}$ & $54[18-500]$ & 26 [18-65] & $42.5[21-500]$ & $29.5[20-175]$ & 27 [18-330] & $0.009^{\star}$ & $0.001^{\star}$ & $0.004^{\star}$ \\
\hline ROM shank ${ }^{b}$ & $\begin{array}{c}37.63 \\
{[10.10-74.12]}\end{array}$ & $\begin{array}{c}66.99 \\
{[26.69-81.71]}\end{array}$ & $\begin{array}{c}48.22 \\
{[11.10-79.21]}\end{array}$ & $\begin{array}{c}62.11 \\
{[20.08-78.48]}\end{array}$ & $\begin{array}{c}67.41 \\
{[14.56-80.04]}\end{array}$ & $0.008^{\star}$ & $<0.001^{\star}$ & $0.006^{\star}$ \\
\hline ROM knee ${ }^{b}$ & $\begin{array}{c}38.05 \\
{[16.30-53.44]}\end{array}$ & $\begin{array}{c}49.20 \\
{[26.76-56.13]}\end{array}$ & $\begin{array}{c}42.01 \\
{[20.31-52.68]}\end{array}$ & $\begin{array}{c}47.38 \\
{[26.71-55.49]}\end{array}$ & $\begin{array}{c}49.12 \\
{[23.55-59.25]}\end{array}$ & $0.005^{\star}$ & $0.003^{\star}$ & $<0.001^{\star}$ \\
\hline Mean stride length ${ }^{\mathrm{b}}$ & $\begin{array}{c}42.38 \\
{[11.22-80.43]}\end{array}$ & $\begin{array}{c}73.30 \\
{[25.92-85.22]}\end{array}$ & $\begin{array}{c}47.21 \\
{[12.36-84.63]}\end{array}$ & $\begin{array}{c}61.06 \\
{[21.22-80.82]}\end{array}$ & $\begin{array}{c}69.60 \\
{[13.60-88.03]}\end{array}$ & $0.012^{\star}$ & $0.001^{\star}$ & 0.028 \\
\hline Mean stride velocity ${ }^{b}$ & $\begin{array}{c}41.20 \\
{[7.17-84.65]}\end{array}$ & $\begin{array}{c}62.27 \\
{[23.31-89.80]}\end{array}$ & $\begin{array}{c}47.44 \\
{[9.97-81.28]}\end{array}$ & $\begin{array}{c}59.67 \\
{[21.83-84.97]}\end{array}$ & $\begin{array}{c}64.93 \\
{[18.76-79.62]}\end{array}$ & 0.078 & $0.003^{\star}$ & 0.053 \\
\hline Mean gait cycle time ${ }^{b}$ & $\begin{array}{c}1.09 \\
{[0.64-1.65]}\end{array}$ & $\begin{array}{c}1.12 \\
{[0.94-1.35]}\end{array}$ & $1.14[0.59-1.45]$ & $\begin{array}{c}1.05 \\
{[0.88-1.36]}\end{array}$ & $\begin{array}{c}1.09 \\
{[0.85-1.35]}\end{array}$ & 0.955 & 0.687 & 0.500 \\
\hline $\begin{array}{l}\text { Swing time asymmetry } \\
(\mathrm{STA})^{\mathrm{b}}\end{array}$ & $\begin{array}{c}3.80 \\
{[0.23-40.57]}\end{array}$ & $\begin{array}{c}7.23 \\
{[0.30-34.82]}\end{array}$ & $7.15[0.24-47.37]$ & $\begin{array}{c}7.17 \\
{[0.92-50.31]}\end{array}$ & $\begin{array}{c}8.02 \\
{[1.09-41.49]}\end{array}$ & 0.041 & 0.687 & 0.679 \\
\hline
\end{tabular}

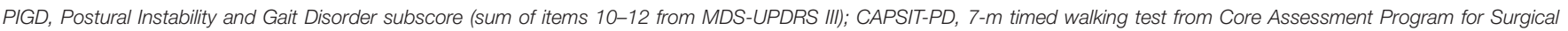

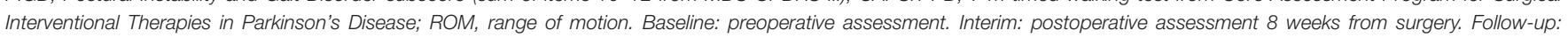

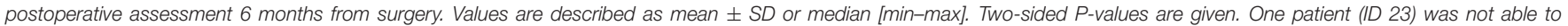
complete CAPSIT-PD at baseline MedOff condition. The kinematic data quality of ID 16 at baseline MedOff and ID 3 at follow-up was not adequate for analysis.

a Sign test.

${ }^{b}$ Wilcoxon signed-rank test.

${ }^{c}$ Paired sample t-test.

*Significant after false discovery rate (FDR) correction (Benjamini-Hochberg).

$=0.012$ ). There was no difference in stride velocity and gait cycle time. Swing time asymmetry worsened after 6 months $(P=0.041$, n.s. after FDR correction).

\section{Comparison of Gait and Freezing of Gait Outcomes in the Freezer Subgroup}

A detailed overview of the statistical descriptives and results of "freezer subgroup" analysis is given in Table 3. The FoG-AC scores at each assessment and condition are given in Figure 2 as box plots.

\section{Preoperative MedOff vs. MedOn}

FoG-AC improved $(P=0.002)$ preoperatively, as well as the CAPSIT-PD in the "number of steps" $(P=0.002)$ and "time" $(P$ $=0.002$ ). Spatiotemporal and kinematic gait parameters showed an improvement of ROM at shank level $(P=0.002)$ and at knee level $(P=0.002)$ as well as stride length $(P=0.002)$ and stride velocity $(P=0.008)$. There was no difference in gait cycle time and swing time asymmetry.

\section{8-Week StimOff vs. StimOn}

With STN-DBS turned on, the FoG-AC improved $(P=0.003)$. CAPSIT-PD showed also an improvement in "number of steps" $(P=0.017)$, "time" $(P=0.006)$, and "number of freezing episodes" ( $P=0.046$, n.s. after FDR correction). Spatiotemporal and kinematic gait parameters showed an improvement of joint
ROM at shank level $(P=0.009)$ and knee level $(P=0.002)$ and of stride length $(P=0.028$, n.s. after FDR correction). There was no difference in stride velocity, gait cycle time, and swing time asymmetry.

\section{Preoperative MedOff vs. 6-Month MedOn/StimOn}

FoG-AC improved between postoperative 6-month follow-up MedOn/StimOn and baseline MedOff $(P=0.003)$. CAPSIT-PD showed improvements in the "number of steps" $(P=0.028)$ and "time" $(P=0.041)$. We observed an improvement of joint ROM at shank level $(P=0.010)$ and knee level $(P=0.010)$, of stride length $(P=0.013)$, and of stride velocity $(P=0.033)$. There was no difference in gait cycle time and swing time asymmetry.

\section{Correlations of Preoperative Scores With Postoperative 6-Month Freezing Outcome in the Freezer Subgroup}

We observed that a favorable outcome of FoG at 6-month follow-up (calculated as improvement of FoG-AC from baseline MedOff to 6-month follow-up MedOn/StimOn) correlated with preoperative severity of FoG in MedOff (defined by FoG-AC score) $(P=0.016)$, as well as with preoperative levodopa response of the FoG-AC $(P<0.001)$ and the preoperative levodopa response of the PIGD subscore $(P=0.004)$.

Among kinematic parameters, preoperative levodopa response of stride length $(P=0.004)$, ROM at shank $(P=$ 
TABLE 3 | Clinical and kinematic data of freezing patients.

\begin{tabular}{|c|c|c|c|c|c|c|c|c|}
\hline & $\begin{array}{l}\text { Baseline } \\
\text { MedOff }\end{array}$ & $\begin{array}{l}\text { Baseline } \\
\text { MedOn }\end{array}$ & $\begin{array}{c}\text { Interim } \\
\text { MedOff/StimOff }\end{array}$ & $\begin{array}{c}\text { Interim } \\
\text { MedOff/StimOn }\end{array}$ & $\begin{array}{l}\text { Follow-up } \\
\text { (FU) }\end{array}$ & $\begin{array}{c}P \text {-value } \\
\text { Baseline Off } \\
\text { vs. FU }\end{array}$ & $\begin{array}{c}P \text {-value } \\
\text { Baseline } \\
\text { Off vs. On }\end{array}$ & $\begin{array}{c}P \text {-value } \\
\text { Interim } \\
\text { Off vs. Or }\end{array}$ \\
\hline MDS-UPDRS $\|^{\mathrm{C}}$ & $49.92 \pm 16.24$ & $26.85 \pm 12.30$ & $51.08 \pm 17.14$ & $34.15 \pm 12.11$ & $31.08 \pm 11.54$ & $<0.001^{*}$ & $<0.001^{\star}$ & $<0.001^{*}$ \\
\hline PIGD subscore ${ }^{c}$ & $6.77 \pm 2.05$ & $2.62 \pm 1.98$ & $5.31 \pm 2.72$ & $3.69 \pm 2.59$ & $2.85 \pm 2.73$ & $<0.001^{*}$ & $<0.001^{\star}$ & $0.019^{*}$ \\
\hline Push and release test ${ }^{a}$ & $2[0-4]$ & $1[0-4]$ & $1[0-3]$ & $1[0-3]$ & 0 [0-3] & $0.012^{\star}$ & 0.125 & 1.000 \\
\hline CAPSIT-PD time ${ }^{b}$ & 38.5 [12-533] & 16 [9-42] & 29 [13-360] & 16 [9-93] & $15[11-257]$ & $0.041^{*}$ & $0.002^{*}$ & $0.006^{\star}$ \\
\hline CAPSIT-PD steps ${ }^{\mathrm{b}}$ & 62.5 [25-500] & 27 [21-65] & 54 [26-500] & 36 [24-175] & 27 [22-330] & $0.028^{*}$ & $0.002^{*}$ & $0.017^{\star}$ \\
\hline CAPSIT-PD freezing ${ }^{b}$ & 0 [0-31] & $0[0-0]$ & $0[0-9]$ & $0[0-8]$ & 0 [0-43] & 0.715 & 0.180 & 0.046 \\
\hline ROM shank ${ }^{b}$ & $\begin{array}{c}36.63 \\
{[10.10-74.12]}\end{array}$ & $\begin{array}{c}66.06 \\
{[26.68-78.95]}\end{array}$ & $\begin{array}{c}40.61 \\
{[11.10-71.86]}\end{array}$ & $\begin{array}{c}53.77 \\
{[20.08-74.32]}\end{array}$ & $\begin{array}{c}67.42 \\
{[14.56-79.69]}\end{array}$ & $0.010^{*}$ & $0.002^{*}$ & $0.009^{*}$ \\
\hline ROM knee ${ }^{b}$ & $\begin{array}{c}34.19 \\
{[16.30-51.25]}\end{array}$ & $\begin{array}{c}49.05 \\
{[26.76-54.04]}\end{array}$ & $\begin{array}{c}39.48 \\
{[20.31-49.05]}\end{array}$ & $\begin{array}{c}44.82 \\
{[26.71-52.81]}\end{array}$ & $\begin{array}{c}49.12 \\
{[23.55-59.25]}\end{array}$ & $0.010^{*}$ & $0.002^{*}$ & $0.002^{*}$ \\
\hline Mean gait cycle time ${ }^{b}$ & $\begin{array}{c}1.05 \\
{[0.64-1.65]}\end{array}$ & $\begin{array}{c}1.15 \\
{[0.94-1.35]}\end{array}$ & 1.07 [0.59-1.45] & $\begin{array}{c}1.01 \\
{[0.88-1.36]}\end{array}$ & $\begin{array}{c}1.08 \\
{[0.85-1.26]}\end{array}$ & 0.594 & 0.937 & 0.507 \\
\hline $\begin{array}{l}\text { Swing time asymmetry } \\
(\text { STA })^{b}\end{array}$ & $\begin{array}{c}4.42 \\
{[0.23-40.57]}\end{array}$ & $\begin{array}{c}6.68 \\
{[0.30-34.82]}\end{array}$ & $6.99[0.31-47.37]$ & $\begin{array}{c}10.11 \\
{[0.92-50.31]}\end{array}$ & $\begin{array}{c}8.03 \\
{[1.09-41.49]}\end{array}$ & 0.213 & 0.530 & 0.249 \\
\hline
\end{tabular}

FoG-AC, Freezing of Gait Assessment Course (Ziegler and colleagues); PIGD, Postural Instability and Gait Disorder subscore (sum of items 10-12 from MDS-UPDRS III); CAPSIT-PD, 7-m timed walking test from Core Assessment Program for Surgical Interventional Therapies in Parkinson's Disease; ROM, range of motion. Baseline: preoperative assessment. Interim: postoperative assessment 8 weeks from surgery. Follow-up: postoperative assessment 6-months from surgery. Values are described as mean $\pm S D$ or median [min-max]. Two-sided P-values are given. One patient (ID 23) was not able to complete CAPSIT-PD at baseline MedOff condition. The kinematic data quality of ID 16 at baseline MedOff and ID 3 at follow-up was not adequate for analysis.

a Sign test.

${ }^{b}$ Wilcoxon signed-rank test.

${ }^{c}$ Paired sample t-test.

*Significant after false discovery rate (FDR) correction (Benjamini-Hochberg).

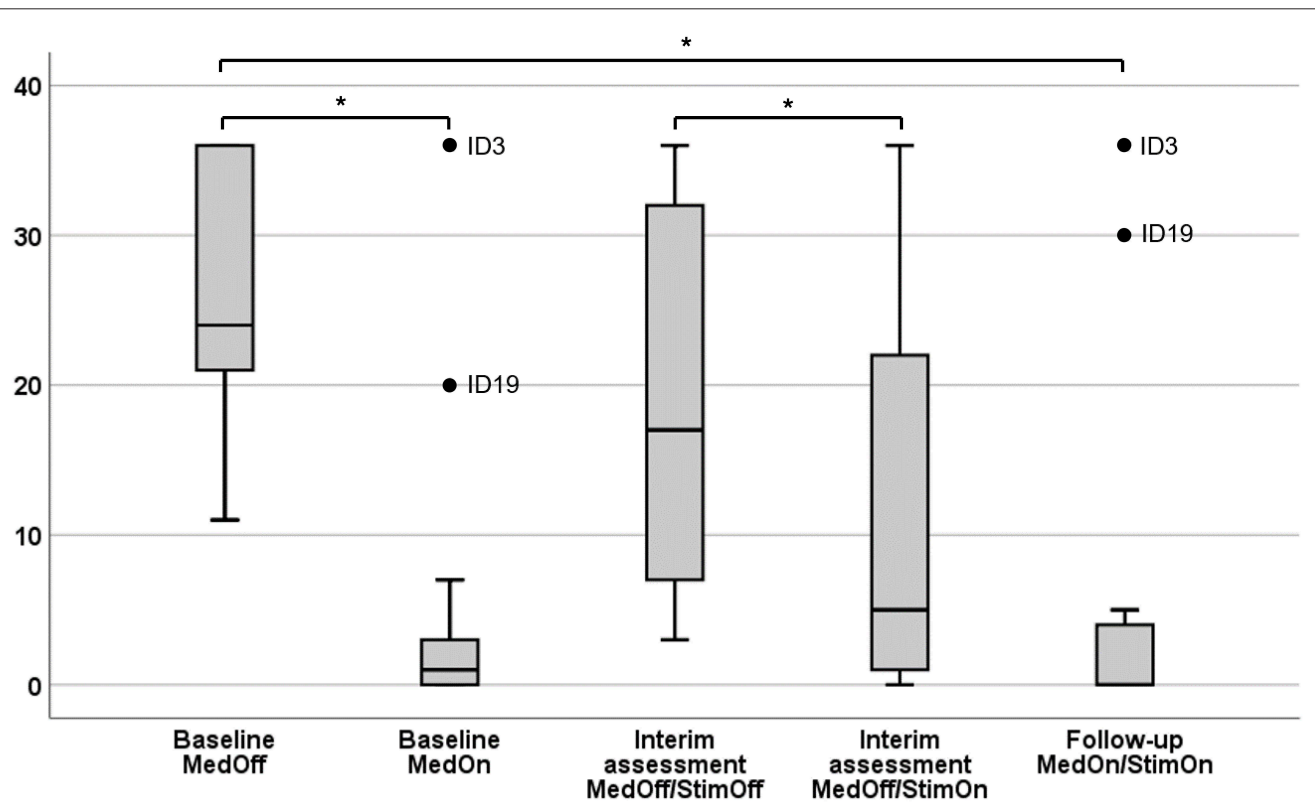

FIGURE 2 | Severity of Freezing Assessment Course in different conditions. Results are given as box plots. $x$-axis, therapeutic condition; $y$-axis, score of the Freezing of Gait Assessment Course. *Significant after false discovery rate (FDR) correction (Benjamini?Hochberg). 
TABLE 4 | Clinical and kinematic variables correlating to favorable FoG outcome.

\begin{tabular}{|c|c|c|}
\hline & $\begin{array}{l}\text { Correlation } \\
\text { coefficient }\end{array}$ & $P$-value \\
\hline Preoperative LEDD & 0.459 & 0.115 \\
\hline Age & 0.177 & 0.562 \\
\hline Disease duration & 0.202 & 0.508 \\
\hline Preoperative severity of UPDRS III in MedOff & -0.028 & 0.929 \\
\hline Preoperative severity of FoG in MedOff & 0.649 & $0.016^{\star}$ \\
\hline Preoperative levodopa response of FoG & 0.957 & $<0.001^{\star}$ \\
\hline $\begin{array}{l}\text { Preoperative levodopa response of PIGD } \\
\text { subscore }\end{array}$ & 0.743 & $0.004^{\star}$ \\
\hline $\begin{array}{l}\text { Preoperative levodopa response of UPDRS } \\
\text { III }\end{array}$ & 0.425 & 0.147 \\
\hline $\begin{array}{l}\text { Preoperative levodopa response of ROM } \\
\text { shank }\end{array}$ & 0.746 & $0.005^{*}$ \\
\hline $\begin{array}{l}\text { Preoperative levodopa response of ROM } \\
\text { knee }\end{array}$ & 0.817 & $0.001^{*}$ \\
\hline $\begin{array}{l}\text { Preoperative levodopa response of stride } \\
\text { length }\end{array}$ & 0.761 & $0.004^{*}$ \\
\hline $\begin{array}{l}\text { Preoperative levodopa response of stride } \\
\text { velocity }\end{array}$ & 0.394 & 0.205 \\
\hline $\begin{array}{l}\text { Preoperative levodopa response of gait } \\
\text { cycle time }\end{array}$ & -0.113 & 0.727 \\
\hline $\begin{array}{l}\text { Preoperative levodopa response of swing } \\
\text { time asymmetry }\end{array}$ & 0.458 & 0.135 \\
\hline
\end{tabular}

FoG-AC, Freezing of Gait Assessment Course (Ziegler and colleagues); PIGD, Postural Instability and Gait Disorder subscore (sum of items 10-12 from MDS-UPDRS III); ROM, range of motion. Two-sided $P$-values are given.

*Significant after false discovery rate (FDR) correction (Benjamini-Hochberg).

$0.005)$, and ROM at knee level $(P=0.001)$ pointed to a favorable outcome of FoG. All correlations are given in Table 4, and the significant correlations can be found in Figure 3.

\section{Prediction of the 6-Month Follow-Up Freezing Outcome From Preoperative Clinical and Kinematic Variables in the Freezer Subgroup}

We included the clinical and kinematic variables to our regression model that showed significant correlation with FoGAC outcomes, namely, the preoperative levodopa response of FoG-AC, preoperative levodopa response of PIGD subscore, preoperative levodopa response of ROM shank, preoperative levodopa response of ROM knee, preoperative levodopa response of stride velocity, and preoperative levodopa response of stride length. The preoperative levodopa response of FoG-AC predicted the postoperative outcome (difference between 6month follow-up in MedOn/StimOn condition and preoperative MedOff condition) to a great extent $\left(R^{2}=0.952,95 \%\right.$ CI: 0.95-1.29, $P<0.001$ ) (Figure 3B). Levodopa response of the other variables did not show significant predictive values (preoperative levodopa response of PIGD subscore $P$ $=0.086$, preoperative levodopa response of $\mathrm{ROM}$ at shank $P=0.508$, preoperative levodopa response of ROM at knee $P=0.666$, preoperative levodopa response of stride velocity $P$ $=0.959$, and preoperative levodopa response of stride length $P=$
0.200 ). In addition, these kinematic variables did not improve the accuracy of our prediction model.

\section{DISCUSSION}

In this prospective study, we found that both clinical and kinematic levodopa responsive gait measures improved after STN-DBS. This was in particular true for the quantitative FoG outcomes in PD freezers. Interestingly, the preoperative response assessed with the fine-grained clinical FoG Assessment Course and the kinematic gait features were associated with a favorable outcome of FoG.

These findings are relevant to improve the preoperative stratification and patient counseling on STN-DBS procedures with respect to gait and FoG. We identified the preoperative severity of FoG in medication off state, as well as the preoperative levodopa response of quantitative FoG assessment and preoperative levodopa response of PIGD subscore as candidate features related to a favorable FoG outcome. Likewise, preoperative levodopa response of ROM at shank and knee levels and that of stride length were also such candidate features among kinematic measures. Previous studies suggested that gait outcomes after STN-DBS are highly heterogeneous with up to $50 \%$ of preoperative "freezers" continuing FoG 1 year after surgery (3) and $42 \%$ in another study (4). Furthermore, FoG seems to worsen substantially under STN-DBS as disease progresses, and reprogramming strategies like low-frequency programming of STN stimulation or interleaved stimulation of $\mathrm{STN}+\mathrm{SNr}$ may lead to partial success $(6,27,31)$. However, the long-term effects of such reprogramming are variable, and definite conclusion cannot be drawn yet on these strategies $(27,31)$. Together, the preoperative stratification process needs refinement in order to identify the patients with favorable gait and FoG outcomes $(32,33)$.

In this sense, one recent meta-analysis found the preoperative levodopa response of the total UPDRS III to predict favorable FoG outcomes on the UPDRS II item 14 on FoG (which reflects narrative information on FoG on the basis of the patients' selfperception) (9). In addition, a recent secondary analysis of the EARLYSTIM-trial showed that $52 \%$ of the patients had FoG preoperatively, and it decreased to $34 \%$ at 24 -month follow-up. Interestingly, patients who stayed as freezers had significantly longer disease duration than had those who became non-freezers (10). As main difference to our study, the EARLYSTIM cohort was younger than our cohort (mean $52.6 \pm 6.3$ years) and had a shorter disease duration (mean $7.5 \pm 2.8$ years) in comparison with our study (mean age $66.9 \pm 6.9$ years and mean disease duration $12.8 \pm 6.8$ years). Further, FoG assessment was based on patient-reported FoG in terms of item 14 of UPDRS II, whereas our study used a quantitative clinical assessment specific to gait as outcome parameter. Similarity between the two studies is a well-preserved levodopa-response of motor symptoms, which is established as a main selection criterion for $\operatorname{DBS}(7,8,34)$. This study, as well as related studies, increasingly support that the importance of levodopa sensitivity also applies for FoG.

However, given that some patients continue to exhibit FoG despite good levodopa response, more specific quantitative outcomes and predictors on gait measures and FoG in specific 


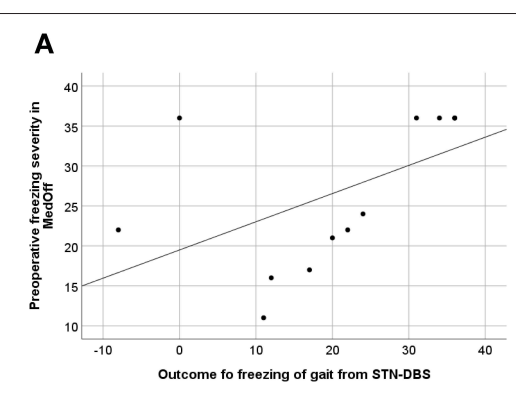

D

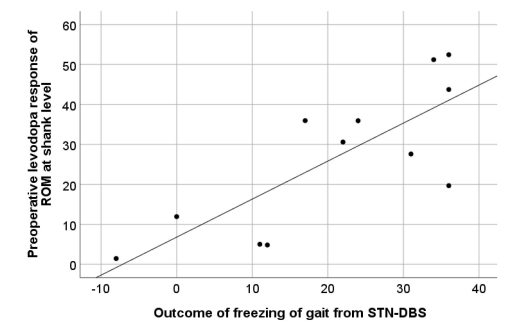

B

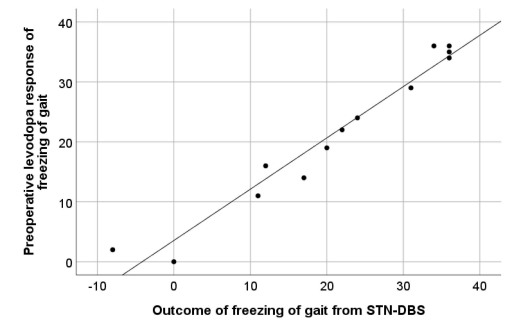

E

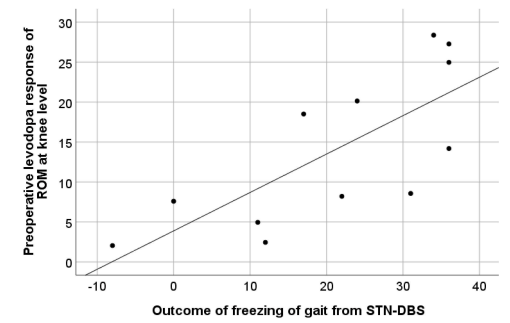

C

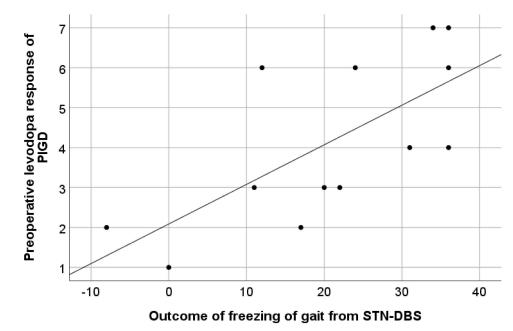

$\mathbf{F}$

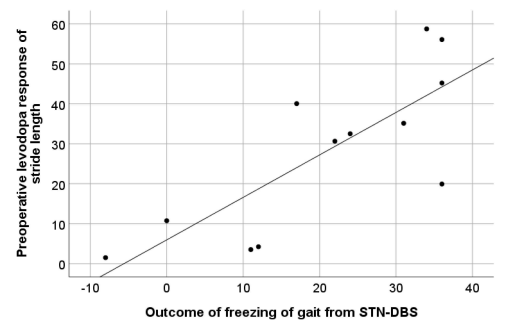

FIGURE 3 | Correlation between freezing of gait (FoG) outcome, calculated as improvement of Freezing of Gait Assessment Course (FoG-AC) from baseline MedOff to follow-up MedOn/StimOn. (A) Preoperative FoG severity in baseline MedOff, defined by FoG-AC score ( $r=0.649$; $P=0.016)$. (B) Preoperative levodopa response of freezing of gait, calculated as improvement of FoG-AC from baseline MedOff to baseline MedOn $(r=0.957 ; P<0.001)$. (C) Preoperative levodopa response of PIGD subscore, calculated as improvement of PIGD subscore from baseline MedOff to baseline MedOn ( $r=0.743 ; P=0.004)$. (D) Preoperative levodopa response of ROM at shank level, calculated as improvement of ROM at shank level from baseline MedOff to baseline MedOn ( $r=0.746 ; P=0.005)$. (E) Preoperative levodopa response of ROM at knee level, calculated as improvement of ROM at knee level from baseline MedOff to baseline MedOn $(r=0.817 ; P=0.001)$. (F) Preoperative levodopa response of stride length, calculated as improvement of stride length from baseline MedOff to baseline MedOn $(r=0.761 ; P=0.004)$.

are needed. Interestingly, the preoperative correlates identified in this study include FoG severity as clinical measure and also spatial kinematic measures like ROM and stride length. This is in good accordance with previous literature that showed modulation of spatial parameters with STN-DBS $(21,35)$. In contrast, we did not find limb asymmetry measures to inform about the 6 months FoG outcomes. This is an important caveat, because acute reprogramming strategies in STN-DBS therapy aim to improve lower limb asymmetry measures in order improve FoG outcomes. But also with STN-DBS reprogramming, asymmetry seems to be a short-term marker (36), whereas its role for stable long-term outcomes is less clear and under ongoing consideration (37). Therefore, the correlates of a stable 6 months gait outcome may be more relevant to overall FoG outcomes, as opposed to short-term neuromodulation effects on gait.

\section{Methodological Considerations and Study \\ Limitations}

This study, in which we aimed to identify correlates of 6 months gait and FoG outcomes in patients treated with STN-DBS, was performed with exploratory intent. Because of this and the fact that this was a single-center study, the sample size was limited. Nevertheless, we focused on narrowing down the clinical and kinematic features that correlated with favorable FoG outcomes. Surely, this is not a final confirmation of these findings. Hence, the prediction model-albeit significant-should be reproduced in a larger cohort. The data from this prospective study provide a good basis to challenge the measures in a larger prediction study.

In this study, FoG outcomes were primarily predicted from the preoperative FoG-AC scores. The kinematic measures did not further improve the prediction accuracy of our model; this should be re-challenged in the future. In particular, our patients showed near-to-full levodopa response of FoG preoperatively. However, this must not necessarily be true in other patients with motor fluctuations referred to STN-DBS. In addition to FoG-AC assessments, other clinical measures of long-term response of FoG should be included, like FoG questionnaire. Eventually, in the future, ambulatory kinematic measurements may enable objective assessments of FoG under daily life conditions to get even superior information on the true outcomes of a highly episodic and context-dependent clinical symptom (11).

Patients with unfavorable gait and FoG outcomes after STN-DBS may have been under-represented in this study given that we found a high rate of responders on gait and FoG measures. This may have been caused by the fact that the $\mathrm{PD}$ patients were selected according to existing clinical criteria, with levodopa-responsive parkinsonism being one core component in the selection process. It was not intended in this study to refer patients outside these stringent criteria for STN-DBS.

The fact that we assessed only MedOn/StimOn condition at follow-up may be seen as a limitation on the one hand, but on the other hand, this therapeutic condition is closest to the 
patients' daily life situation and, therefore, most representative for the true therapeutic outcome. Withdrawal and reinsertion of levodopa at the 6-month follow-up would have enabled the evaluation of pure stimulation effect. However, it would have been less representative for the true daily life outcome, because of the artificial condition induced by reinsertion of immediate release levodopa. This was the main reason for our choice.

\section{CONCLUSION}

In summary, our findings show that favorable outcomes on gait and FoG from STN-DBS are achieved if quantitative FoG measures, stride length, and ROM at shank and knee levels show robust preoperative levodopa response. This study provides novel candidate features specific to gait and FoG that should be re-evaluated and reproduced as predictive stratification model in order to facilitate gait outcomes in STN-DBS for PD.

\section{DATA AVAILABILITY STATEMENT}

The datasets generated for this study are available on request to the corresponding author.

\section{REFERENCES}

1. Pickering RM, Grimbergen YA, Rigney U, Ashburn A, Mazibrada G, Wood B, et al. A meta-analysis of six prospective studies of falling in Parkinson's disease. Mov Disord. (2007) 22:1892-900. doi: 10.1002/mds.21598

2. Forsaa EB, Larsen JP, Wentzel-Larsen T, Herlofson K, Alves G. Predictors and course of health-related quality of life in Parkinson's disease. Mov Disord. (2008) 23:1420-7. doi: 10.1002/mds.22121

3. Vercruysse S, Vandenberghe W, Munks L, Nuttin B, Devos H, Nieuwboer A. Effects of deep brain stimulation of the subthalamic nucleus on freezing of gait in Parkinson's disease: a prospective controlled study. J Neurol Neurosurg Psychiatry. (2014) 85:871-7. doi: 10.1136/jnnp-2013-306336

4. Karachi C, Cormier-Dequaire F, Grabli D, Lau B, Belaid H, Navarro $\mathrm{S}$, et al. Clinical and anatomical predictors for freezing of gait and falls after subthalamic deep brain stimulation in Parkinson's disease patients. Parkinsonism Relat Disord. (2019) 62:91-7. doi: 10.1016/j.parkreldis.2019.01.021

5. Fleury V, Pollak P, Gere J, Tommasi G, Romito L, Combescure C, et al. Subthalamic stimulation may inhibit the beneficial effects of levodopa on akinesia and gait. Mov Disord. (2016) 31:1389-97. doi: 10.1002/mds.26545

6. Lau B, Meier N, Serra G, Czernecki V, Schuepbach M, Navarro S, et al. Axial symptoms predict mortality in patients with Parkinson disease and subthalamic stimulation. Neurology. (2019) 92:e2559-e70. doi: 10.1212/WNL.0000000000007562

7. Deuschl G, Schade-Brittinger C, Krack P, Volkmann J, Schafer H, Botzel $\mathrm{K}$, et al. A randomized trial of deep-brain stimulation for Parkinson's disease. $N$ Engl J Med. (2006) 355:896-908. doi: 10.1056/NEJMoa0 60281

8. Schuepbach WM, Rau J, Knudsen K, Volkmann J, Krack P, Timmermann L, et al. Neurostimulation for Parkinson's disease with early motor complications. N Engl J Med. (2013) 368:610-22.

9. Schlenstedt C, Shalash A, Muthuraman M, Falk D, Witt K, Deuschl G. Effect of high-frequency subthalamic neurostimulation on gait and freezing of gait in Parkinson's disease: a systematic review and meta-analysis. Eur J Neurol. (2017) 24:18-26. doi: 10.1111/ene.13167

\section{ETHICS STATEMENT}

The studies involving human participants were reviewed and approved by University of Tübingen. The patients/participants provided their written informed consent to participate in this study.

\section{AUTHOR CONTRIBUTIONS}

IC, AG, and DW designed and conceptualized the study. IC, MS, and DW analyzed and interpreted data. IC, MS, AG, and DW drafted and revised the manuscript for intellectual content.

\section{ACKNOWLEDGMENTS}

We would like to thank Dr. Christoph Meisner (Institute for Clinical Epidemiology and Applied Biometry at the University of Tubingen) for statistical advice.

\section{SUPPLEMENTARY MATERIAL}

The Supplementary Material for this article can be found online at: https://www.frontiersin.org/articles/10.3389/fneur. 2020.00212/full\#supplementary-material

10. Barbe MT, Tonder L, Krack P, Debu B, Schupbach M, Paschen S, et al. Deep brain stimulation for freezing of gait in Parkinson's Disease with early motor complications. Mov Disord. (2019) 35:82-90. doi: 10.1002/mds.27892

11. Mancini M, Bloem BR, Horak FB, Lewis SJG, Nieuwboer A, Nonnekes J. Clinical and methodological challenges for assessing freezing of gait: Future perspectives. Mov Disord. (2019) 34:783-90. doi: 10.1002/mds. 27709

12. Sanchez-Ferro A, Maetzler W. Advances in sensor and wearable technologies for Parkinson's disease. Mov Disord. (2016) 31:1257. doi: 10.1002/mds.26746

13. Hausdorff JM, Cudkowicz ME, Firtion R, Wei JY, Goldberger AL. Gait variability and basal ganglia disorders: stride-to-stride variations of gait cycle timing in Parkinson's disease and Huntington's disease. Mov Disord. (1998) 13:428-37. doi: 10.1002/mds.870130310

14. Plotnik M, Giladi N, Balash Y, Peretz C, Hausdorff JM. Is freezing of gait in Parkinson's disease related to asymmetric motor function? Ann Neurol. (2005) 57:656-63. doi: 10.1002/ana.20452

15. Ricciardi L, Ricciardi D, Lena F, Plotnik M, Petracca M, Barricella S, et al. Working on asymmetry in Parkinson's disease: randomized, controlled pilot study. Neurol Sci. (2015) 36:1337-43. doi: 10.1007/s10072-015-2082-8

16. Ferrarin M, Rizzone M, Bergamasco B, Lanotte M, Recalcati M, Pedotti A, et al. Effects of bilateral subthalamic stimulation on gait kinematics and kinetics in Parkinson's disease. Exp Brain Res. (2005) 160:517-27. doi: 10.1007/s00221-004-2036-5

17. Krystkowiak P, Blatt JL, Bourriez JL, Duhamel A, Perina M, Blond S, et al. Effects of subthalamic nucleus stimulation and levodopa treatment on gait abnormalities in Parkinson disease. Arch Neurol. (2003) 60:80-4. doi: 10.1001/archneur.60.1.80

18. Xie J, Krack P, Benabid AL, Pollak P. Effect of bilateral subthalamic nucleus stimulation on parkinsonian gait. J Neurol. (2001) 248:1068-72. doi: 10.1007/s004150170027

19. Stolze H, Klebe S, Poepping M, Lorenz D, Herzog J, Hamel W, et al. Effects of bilateral subthalamic nucleus stimulation on parkinsonian gait. Neurology. (2001) 57:144-6. doi: 10.1212/WNL.57.1.144

20. Johnsen EL, Mogensen PH, Sunde NA, Ostergaard K. Improved asymmetry of gait in Parkinson's disease with DBS: gait and postural instability in 
Parkinson's disease treated with bilateral deep brain stimulation in the subthalamic nucleus. Mov Disord. (2009) 24:590-7. doi: 10.1002/mds.22419

21. Collomb-Clerc A, Welter ML. Effects of deep brain stimulation on balance and gait in patients with Parkinson's disease: a systematic neurophysiological review. Neurophysiol Clin. (2015) 45:371-88. doi: 10.1016/j.neucli.2015.07.001

22. Faist M, Xie J, Kurz D, Berger W, Maurer C, Pollak P, et al. Effect of bilateral subthalamic nucleus stimulation on gait in Parkinson's disease. Brain. (2001) 124:1590-600. doi: 10.1093/brain/124.8.1590

23. Hausdorff JM, Gruendlinger L, Scollins L, O’Herron S, Tarsy D. Deep brain stimulation effects on gait variability in Parkinson's disease. Mov Disord. (2009) 24:1688-92. doi: 10.1002/mds.22554

24. Deuschl G, Schupbach M, Knudsen K, Pinsker MO, Cornu P, Rau J, et al. Stimulation of the subthalamic nucleus at an earlier disease stage of Parkinson's disease: concept and standards of the EARLYSTIM-study. Parkinsonism Relat Disord. (2013) 19:56-61. doi: 10.1016/j.parkreldis.2012.07.004

25. Ziegler K, Schroeteler F, Ceballos-Baumann AO, Fietzek UM. A new rating instrument to assess festination and freezing gait in Parkinsonian patients. Mov Disord. (2010) 25:1012-8. doi: 10.1002/mds.22993

26. Jacobs JV, Horak FB, Van Tran K, Nutt JG. An alternative clinical postural stability test for patients with Parkinson's disease. J Neurol. (2006) 253:140413. doi: 10.1007/s00415-006-0224-x

27. Weiss D, Walach M, Meisner C, Fritz M, Scholten M, Breit S, et al. Nigral stimulation for resistant axial motor impairment in Parkinson's disease? A randomized controlled trial. Brain. (2013) 136(Pt 7):2098-108. doi: 10.1093/brain/awt122

28. Salarian A, Russmann H, Vingerhoets FJ, Dehollain C, Blanc Y, Burkhard $\mathrm{PR}$, et al. Gait assessment in Parkinson's disease: toward an ambulatory system for long-term monitoring. IEEE Trans Biomed Eng. (2004) 51:1434-43. doi: 10.1109/TBME.2004.827933

29. Snijders AH, Haaxma CA, Hagen YJ, Munneke M, Bloem BR. Freezer or non-freezer: clinical assessment of freezing of gait. Parkinsonism Relat Disord. (2012) 18:149-54. doi: 10.1016/j.parkreldis.2011.09.006

30. Benjamini Y, Hochberg Y. Controlling the false discovery rate - a practical and powerful approach to multiple testing. J R Stat Soc B. (1995) 57:289-300. doi: 10.1111/j.2517-6161.1995.tb02031.x

31. Ricchi V, Zibetti M, Angrisano S, Merola A, Arduino N, Artusi CA, et al. Transient effects of $80 \mathrm{~Hz}$ stimulation on gait in STN DBS treated PD patients: a 15 months follow-up study. Brain Stimul. (2012) 5:388-92. doi: 10.1016/j.brs.2011.07.001

32. Muller M, Marusic U, van Emde Boas M, Weiss D, Bohnen NI. Treatment options for postural instability and gait difficulties in Parkinson's disease. Expert Rev Neurother. (2019) 19:1229-1251. doi: 10.1080/14737175.2019.1656067

33. Weiss D, Schöllmann A, Fox MD, Bohnen NI, Factor SA, Nieuwboer A, et al. Freezing of gait - understanding complexity of an enigmatic phenomenon. Brain. (2019) 143:14-30. doi: 10.1093/brain/awz314

34. Deuschl G, Follett KA, Luo P, Rau J, Weaver FM, Paschen S, et al. Comparing two randomized deep brain stimulation trials for Parkinson's disease. J Neurosurg. 2019:1-9. doi: 10.3171/2018.12.JNS1 82042

35. Cossu G, Pau M. Subthalamic nucleus stimulation and gait in Parkinson's disease: a not always fruitful relationship. Gait Posture. (2017) 52:205-10. doi: 10.1016/j.gaitpost.2016.11.039

36. Fasano A, Herzog J, Seifert E, Stolze H, Falk D, Reese R, et al. Modulation of gait coordination by subthalamic stimulation improves freezing of gait. Mov Disord. (2011) 26:844-51. doi: 10.1002/mds. 23583

37. Meoni S, Debu B, Pelissier P, Scelzo E, Castrioto A, Seigneuret E, et al. Asymmetric STN DBS for FOG in Parkinson's disease: a pilot trial. Parkinsonism \& related disorders. (2019) 63:94-9. doi: 10.1016/j.parkreldis.2019.02.032

Conflict of Interest: IC, MS, AG report no disclosures relative to the research covered in the submitted manuscript. DW received research grants from the German Research Council (DFG, WE5375/1-1, WE5375/1-3) and research funding from Medtronic, as well as speakers honoraria/travel grants from Medtronic, Abott (St. Jude), Boston Scientific, and Abbvie.

Copyright (c) 2020 Cebi, Scholten, Gharabaghi and Weiss. This is an open-access article distributed under the terms of the Creative Commons Attribution License (CC $B Y)$. The use, distribution or reproduction in other forums is permitted, provided the original author(s) and the copyright owner(s) are credited and that the original publication in this journal is cited, in accordance with accepted academic practice. No use, distribution or reproduction is permitted which does not comply with these terms. 